\title{
Live Streaming Commerce: Uses and Gratifications Approach to Understanding Consumers' Motivations
}

\author{
Jie Cai \\ New Jersey Institute of Technology \\ Newark, NJ, USA \\ jc926@njit.edu
}

\author{
Donghee Yvette Wohn \\ New Jersey Institute of Technology \\ Newark, NJ, USA \\ wohn@njit.edu
}

\begin{abstract}
In this paper, we introduce live streaming commerce- e-commerce integrated with real-time social interaction via live streams. Using a uses and gratifications framework, we identified four motivations (enjoyment of interaction, substitutability of personal examination, need for community, and trend setting) related to live streaming commerce, and explored relationships between motivations and behavioral intentions in three different scenarios: general watching scenario, product search scenario, and internet celebrity scenario. Results showed that substitutability of personal examination was associated with the general watching scenario and product search scenario, while enjoyment of interaction was associated with the internet celebrity scenario. Trend setting was associated with all scenarios but need for community was insignificant with all scenarios. Design implications based on results are discussed for future live streaming commerce system development.
\end{abstract}

\section{Introduction}

Live streaming has become extremely popular in recent years, spurring a lot of research around this topic. Some research has focused on technical issues of live streaming systems $[30,42,43]$; other research was about user-generated content, streamers' motives, and viewers' motives [14, 35]; and some research focused on specific platforms such as YouTube Live [13, 30], Twitch [14, 22, 30, 44], and Periscope [10, 41]. In 2007, Friedländer [10] identified that the main categories of live streaming content are chatting, sharing information, 24/7 (i.e., webcams), "slice of life", and entertainment media, on the basis of content from three different countries (Germany, United States, and Japan) across different platforms (YouNow, Periscope, and Ustream). Missing from this analysis, however, was live streaming commerce.
Shopping with live streams-also known as live streaming commerce-is comparatively new. Live streaming commerce is defined as a subset of ecommerce embedded with real-time social interaction, a feature unique to live streams [2]. There are two types of live streaming commerce. The first is when live streaming features are introduced into e-commerce/ shopping sites or apps. Some startups have come into this business and targeted specific market segmentations, such as Livby, which launched the first U.S. mobile live streaming shopping app in 2016 [31]. Other examples include Popshop Live, which allows creative individuals to create their own shopping channels, build their personal brands, and sell products globally [48] and Shopshops, which focuses on connecting U.S. brands with Chinese consumers via live streams [46].

Another example for e-commerce expanding into live streams was Amazon's "Style Code Live" (see Figure 1 for example) which was launched in 2016 to broadcast fashion and beauty products to its customers but canceled its service in May 2017 [39]. Amazon was the first American e-commerce giant to get involved in live streaming commerce, albeit unsuccessfully. More recently, Talkshoplive, a startup launched in March 2018, started to support small business owners to live stream their products and connect them to mainstream brands and influencers [40].

The second type of live streaming commerce is when platforms that were originally for live streams integrate commercial activities. In Oct. 2016, "Live.me", a live video chat platform, launched an official store, where users could buy the items promoted by their favorite creators while still keeping one eye on the stream. Another example is Twitch, which is a live streaming platform that is not primarily about selling products, but streamers can have links in their channels that lead to shopping sites and receive commissions. Viewers can also buy virtual products called bits with real money to "cheer" streamers that they appreciate.

While the use of live streaming for shopping is still in its infancy in the United States, e-commerce is one of the most popular applications for live streaming in 


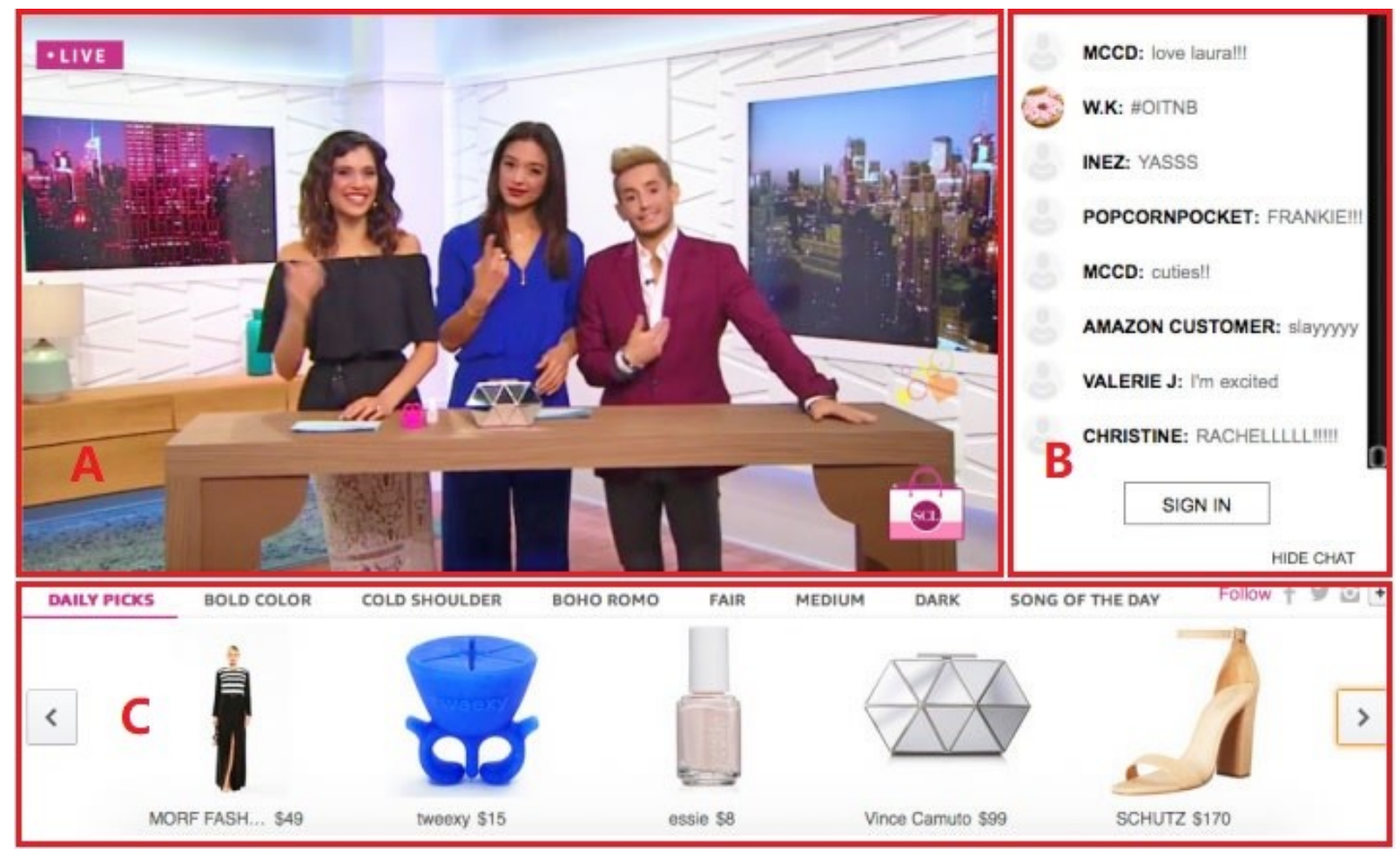

Figure 1. Screenshot of the now-defunct PC webpage of Amazon "Style Code Live". (A): Streamers are introducing products via live stream. (B): On the right, there is a chatroom for viewers to interact with streamers and other viewers. (C): The recommended product links related to the stream.

Image Source: engadget.com

China. More and more e-commerce businesses are joining live streaming shopping [26]. Almost all the main e-commerce platforms have opened live streaming channels such as Taobao.com, JD.com, VIP.com, and Mogujie.com. They often promote an event by inviting social media influencers or stars (internet celebrities) or directly cooperate with brands to broadcast the products. For example, Starbucks streamed its new store opening on Taobao and attracted 180,000 viewers in three hours; Tmall.com exclusively streamed the event of iPhone $\mathrm{X}$ release in China [28]. Taobao Live, which is operated by Alibaba, has already had more than 10,000 internet celebrities introduce and promote all kinds of products through live streams such as makeup, clothing, and food [9].

Despite growing popularity, live streaming commerce research has been limited. This could be because live streaming shopping is flourishing in China but just started in the United States. In one of the few known examples of scholarship on this topic, Cai et al. [2] explored live streaming shopping attitudes and found out that the top four reasons consumers preferred to shop through live streams rather than traditional online shopping were product demonstration (the ability to see how products worked), product information (the ability to ask more information that they are interested in), excitement about novelty of a new way to shop, and interaction (the ability to communicate with the streamer and other viewers).

In this study, we will apply uses and gratifications as the theoretical background and preliminarily explore the motivations to use live streaming commerce and examine how these motivations predict behavioral intentions to engage in live streaming commerce in the future. We first summarize the current research about motives of using live streams, then introduce the concept of live streaming commerce and uses and gratifications theory integrated into online shopping. Finally, results of an online survey are presented, and design implications are discussed.

\section{Theoretical framework}

\subsection{Motivation of using live streams}

Because live streaming commerce is a new phenomenon in online shopping, there is limited research on it. Most existing research is about general motivations of live streamers and/or viewers. Friedländer [10] did research to measure streamers' motivations on social live streaming services $(\mathrm{N}=7,667)$ across different platforms and countries and found that, 
in general, the variety is huge and top six (higher than $10 \%)$ motives are boredom (21.8\%), socializing $(16.38 \%)$, to reach a specific group $(15.2 \%)$, need to communicate $(14.70 \%)$, fun $(13.5 \%)$, and selfexpression $(11.02 \%)$.

Hamilton et al. [14] studied streaming on Twitch, which specialized in gaming, and concluded that there were two reasons for people to engage in live streams: unique content and interaction/ participation. For the streamers, desire to build community and encouragement of participation with viewers were their motivations. For the viewers, three motives were identified through interviews: intention to learn about a particular game, friendliness of the streamers, and social interaction.

Other related research did not distinguish the motivations between streamers and viewers and just looked at the general motivations of users. For instance, a research study about YouNow (a social live streaming service) on which almost half of users were both streamers and viewers, showed that the main motivations to use this platform were ease of use, satisfaction of the need of self-presentation, boredom, and acceptance by the community [35]. Bründl and Hess [1] synthesized five motivations for content contribution of live streaming platforms: enjoyment, self-expression and identity, information dissemination, monetary incentives, and social interaction and community.

These studies give us a general idea of why people engage in live streams, but do not give us specific information about the context of live streaming commerce.

\subsection{What is live streaming commerce?}

Social media refers to a group of Internet-based applications built on the ideological and technological foundations of Web 2.0, that allows for creation and exchange of user-generated content. Scheibe et al. [35] mentioned that social networking sites was a narrower term of social media and could be categorized into asynchronous [23] and synchronous [19]. Live streaming is a synchronous social media, some research call it mixed media [14], that contains some unique features such as simultaneity [35] and authenticity [41], which makes it different from asynchronous social media such as Facebook and Twitter.

Social commerce refers to a method of commerce mediated by social media [36]. Marsden [27] defined social commerce as a subset of e-commerce: it uses social network sites for social interactions to facilitate online shopping. Kim and Park [24] defined social commerce as a new business model of e-commerce driven by social media facilitating the purchasing and selling of product and service. Two types of social commerce were identified: one was e-commerce equipped with Web 2.0 such as Amazon and another was social networking sites integrated with e-commerce feature $[16,24]$. For the first type of social commerce, customers could participate and create content such as comments and reviews, tag, and recommendation lists. For the second type, consumers could use word of mouth to share information with the networked community. However, social commerce is still limited (mostly) to asynchronous social interaction.

Shopping through live streams is a new way of shopping and contains not only lots of social commerce attributes but also unique social media attributes. Cai et al. [2] defined live streaming commerce as e-commerce that integrates real-time social interaction through live streams. From this perspective, we could analogously understand live streaming commerce, from Kim and Park's social commerce definition [24], as a subset of ecommerce that uses live streams for real-time social interactions to facilitate shopping. Real-time interaction among steamers and viewers is the main attribute of live streaming commerce.

Understanding live streaming commerce from perspectives of both social media and e-commerce helps us identify theories that could be applied in these domains to our research.

\subsection{Uses and gratifications approach to understanding live streaming commerce}

Since live streaming commerce can be both from the perspective of the streamer as well as the consumer (i.e., the viewer of the live stream), we will focus on consumers' motivations in this research. However, little research has been done on live streaming commerce specifically, so we turned to literature on motivations of using e-commerce and social media, respectively. As for media use, uses and gratifications theory is widely used as a guiding approach to understanding consumers' needs to use media [33, 34]. Uses and gratifications specifically refers to the motivations of media use and the satisfactions people got from such use [18]. Katz et al. [20] summarized that audience's media usage originally started from the social and psychological needs and finally led to need gratification and other consequences. They identified four basic dimensions of gratifications: information, personal identity, entertainment, and social interaction [21]. The framework has been used extensively to explain social media usage on many platforms such as Twitter [4], MySpace [32], and WeChat [3]. For example, Joinson [18] identified six unique motivations of Facebook usage: social connection, shared identities, content, social investigation, social network surfing, and status 
updating. On YouTube, people viewed video for information seeking, shared video for entertainment, and co-viewed for social interaction [15]. The social media adoption was positively related to personal integrative needs, social integrative needs, and tension release needs [47].

As for live streams, most current research discussed the gratifications of social live streaming services by using Twitch (game genre) as an example. Sjöblom et al. [38] investigated the gratification in the context of live gaming and categorized six gratifications: affective, information seeking, learning to play, personal integrative, social integrative, and tension release. Sjöblom and Hamari [37] examined five gratifications of why viewers watched live video game: cognitive, affective, personal integrative, social integrative, and tension release. Gros et al. [12] found out that the motivations of Twitch users are information, entertainment, and socialization.

Uses and gratifications theory has been applied to explain online shopping intentions as well. Generally, information, interactive control, and socialization could predict online shopping intention [17]. Entertainment gratification and informativeness gratification were positively related to attitude toward online shopping in Malaysia [25]. Another study found that intention to engage in social commerce was positively influenced by information quality, the cool and new trend, and perceived enjoyment [7]. Chinese consumers' social commerce intentions were predicted by perceived gratification from entertainment, information seeking, expressive information sharing, cool and new trends, and social interaction [45].

Since live streaming commerce is a type of ecommerce that contains some attributes of live streams and the ultimate goal for users to use live streaming commerce is purchasing, which is more relevant to ecommerce, we would mainly apply gratifications from online shopping domains and partially combine dimensions related to social media and social live streaming services.

The summary of the application of uses and gratifications theory in both social media and online shopping domains would guide us to adapt and develop items and scales that would be appropriate for the live streaming commerce context.

\section{Research questions}

In this research, first we tried to identify the motivations of viewers and other related factors to shop through live streams. We were interested in the reasons why people would engage in live streaming commerce from a consumer's perspective. Our first research question was:

RQ1: What are the motivations for consumers to watch live streams when they shop?

Our second research question wanted to know how these motivations would be related to people's intentions to watch live streams again in the future when they are shopping. We had three different types of intention: a general intention question, and two questions that were hypothetical scenarios:

RQ2: How do motivations predict these intentions?

- Intention to watch a live stream when shopping in the future?

- Intention to watch a live stream if an individual is searching for a product online and just happens to find a live streaming event?

- Intention to watch a live stream if a shopping website invited your favorite internet celebrity to stream an event for an hour?

\section{Methods}

\subsection{Participants}

We conducted a survey to answer our research questions. All survey questions were approved by the Institutional Review Board and distributed on Amazon Mechanical Turk. Because most live streaming platforms required that users must be around 18 years old, we set that only participants who were $18+$ year are eligible to start the survey. In order to ensure data quality, we set that only Turkers with an approval rate higher than $90 \%$ were qualified. Because live streaming commerce is comparably new in the U.S. and only a small group of consumers might have similar shopping experiences, we set two qualifiers at the beginning of the survey and asked: "Have you ever used a shopping website that had a live stream?" and "Have you ever watched a live stream about a product before purchasing it?" Participants had to answer "yes" to both before even starting the survey. Participants were paid \$2.

A total of 220 responses were collected. After cleaning data and eliminating responses with substantial missing values, we finally maintained 199 valid responses. The participants were from 13 countries and the majority of them were from the U.S. (78.4\%). The average age was $31.7(S D=7.89)$, ranging from 18 to 63. Most of them were from 25 to 34, accounting for $64.8 \%$. 61.8\% were males and $37.2 \%$ were females. $58.2 \%$ had a bachelor's degree or higher. Most participants were full-time employed (73.4\%) and 
almost half of them had yearly household income below $\$ 50,000(52.3 \%)$.

\subsection{Measures}

The survey contained items to measure participants' motivations and intentions. The measurement of each motivation was constructed using multi-item additive indices that assessed different aspect of the variable. After reviewing the aforementioned literature and incorporating the repeated motivations in live streams, social media, and e-commerce context, we focused on constructs that would apply to the live streaming commerce context: variables related to interaction, community, product information, and novelty.

All motivational items were adapted or originally developed by referring to prior literature while being mindful of the live streaming context. Enjoyment of interaction was an original scale measuring the enjoyment or pleasure of interaction among streamers and viewers and developed by referring to items of perceived enjoyment [8] and social interaction ties [6]. Substitutability of personal examination was an adapted scale measuring the ability to substitute for the absence of sensory inputs without touching a physical product. The items were directly borrowed from [5] to fit the context of live streaming commerce. Need for community was an original scale measuring the level that people want to belong to online community and to interact with one another and developed by referring to themes of community [29]. Trend setting was an original scale measuring the degree to which users liked initiating or leading a trend and developed by referring to items from cool and new trend [11]. All items were prefaced with "I watched a live stream before purchasing a product because ..." and responses were measured on a 5-point Likert-type scale from "Strongly disagree" to "Strongly agree".

We also asked questions about how often people shop online and watch live streams to understand general shopping frequency. We asked, "In the past six months, how frequently did you shop online through a website or shopping app?" "In the past six months, how frequently did you shop online after watching a live stream on a shopping website?" "In the past six months, how frequently did you shop online after watching a live stream that was not part of the shopping website? (e.g., watching a live stream on Twitch and then buying the product on Amazon)" "In the past six months, how frequently did you watch live streams (in general)?" The answers were an ordinal scale: "Never" "Once," "Two or three times over six months," "Four to five times over

Table 1: Exploratory factory analysis of motivations for live streaming commerce

\begin{tabular}{|c|c|c|c|c|}
\hline \multirow{2}{*}{$\begin{array}{l}\text { "I watched a live stream before purchasing a product because..." * } \\
\text { Enjoyment of interaction }(M=3.92, S D=.77, \alpha=.87)\end{array}$} & \multicolumn{4}{|c|}{ Factor loadings } \\
\hline & & & & \\
\hline I enjoy chatting during the live stream & .78 & .14 & .16 & .15 \\
\hline I can talk to other people & .77 & .08 & .17 & .25 \\
\hline I like the social experience & .77 & .10 & .21 & .23 \\
\hline I like interacting with the streamer & .74 & .24 & .23 & .04 \\
\hline I can interact with other people online & .66 & .31 & .12 & .28 \\
\hline \multicolumn{5}{|l|}{ Substitutability of personal examination $(M=4.03, S D=.63, \alpha=.81)$} \\
\hline $\begin{array}{l}\text { It would allow me to form an impression about a product similar to that from up-close } \\
\text { examination }\end{array}$ & .18 & .77 & -.14 & .08 \\
\hline $\begin{array}{l}\text { Information available through using live streaming is a good substitute for that } \\
\text { available from seeing and touching the product }\end{array}$ & .21 & .75 & -.01 & .01 \\
\hline $\begin{array}{l}\text { It will offer knowledge of a product similar to that available from an up-close personal } \\
\text { examination }\end{array}$ & .03 & .72 & .07 & .02 \\
\hline $\begin{array}{l}\text { It would deliver information about a product's materials and workmanship similar to } \\
\text { that available from an up-close examination }\end{array}$ & .13 & .71 & -.06 & .25 \\
\hline $\begin{array}{l}\text { It would allow me to judge a product's quality as accurately as an in-person appraisal } \\
\text { of the product }\end{array}$ & .14 & .69 & .04 & .22 \\
\hline \multicolumn{5}{|l|}{ Need for community $(M=3.16, S D=1.10, \alpha=.90)$} \\
\hline I need to get in contact with new people online all the time & .23 & .01 & .88 & .10 \\
\hline I need to interact online to give myself new people to talk to & .21 & -.03 & .87 & .19 \\
\hline I need to spend time to support general online community activity & .24 & -.09 & .82 & .20 \\
\hline \multicolumn{5}{|l|}{ Trend setting $(M=3.95, S D=.71, \alpha=.74)$} \\
\hline I like to shop here so as to keep up with trends & .07 & .05 & .32 & .73 \\
\hline I like to experience new ways of doing things & .33 & .14 & .01 & .72 \\
\hline Live streaming is a new way to shop & .14 & .10 & .24 & .65 \\
\hline I like to explore new technologies & .30 & .31 & .01 & .61 \\
\hline
\end{tabular}


six months," "About once a month," "Two or three times a month," "About once a week," "Two or three times a week," and "Four or more times a week". Demographic questions, including age, race, gender, household income, education level, and employment status, were asked at the end of the survey.

The dependent variables were intentions about
For the first research question, we ran a principal components analysis using varimax rotation to obtain four components with eigenvalues greater than one and factor loadings above .5. These four factors explained $65 \%$ of total variance. The reliability for all scales was satisfactory with a Cronbach's $\alpha$ above .70. Results are reported in Table 1.

\begin{tabular}{|c|c|c|c|}
\hline \multicolumn{4}{|c|}{ Table 2: Linear regression models in three different scenarios } \\
\hline & $\begin{array}{l}\text { General } \\
\text { Scenario }\end{array}$ & $\begin{array}{l}\text { Product } \\
\text { Scenario }\end{array}$ & $\begin{array}{l}\text { Celebrity } \\
\text { Scenario }\end{array}$ \\
\hline \multicolumn{4}{|l|}{ Motivations } \\
\hline Enjoyment of interaction & .02 & .07 & $.24^{\star \star}$ \\
\hline Substitutability of personal examination & $.46^{* \star *}$ & $.22^{\star *}$ & .01 \\
\hline Need for community & .11 & .06 & .16 \\
\hline Trend setting & $.18^{*}$ & $.25^{* *}$ & $.18^{*}$ \\
\hline \multicolumn{4}{|l|}{ Behavioral patterns (Frequency of...) } \\
\hline Shopping online through a website or shopping app & .05 & .08 & .05 \\
\hline Shopping online after watching a live stream on a shopping website & -.01 & -.07 & .13 \\
\hline $\begin{array}{l}\text { Shopping online after watching a live stream that was not part of the } \\
\text { shopping website }\end{array}$ & -.08 & -.01 & $-.18^{*}$ \\
\hline Watching live streams in general & $.16^{*}$ & .12 & .06 \\
\hline \multicolumn{4}{|l|}{ Demographic factors } \\
\hline Age & $.16^{* *}$ & .07 & .01 \\
\hline Gender & .11 & .02 & .04 \\
\hline Household income & .02 & .11 & .11 \\
\hline Adjusted $R^{2}$ & $.40^{\star \star \star}$ & $.22^{\star \star \star}$ & $.22^{* * *}$ \\
\hline
\end{tabular}

whether they might use live streaming commerce in the future if possible. The questions used a 5-point Likert scale from "Very unlikely" to "Very likely". The first intention was about watching live streams for shopping in general and asked, "How likely are you to watch a live stream when shopping in the future?" $(M=4.20$, $S D=.80)$; the second and third were based on specific scenarios: one was involved in product search and asked: "If you are searching for a product online and just happened to find a live streaming event, how likely would you watch it?" $(M=4.25, S D=.70)$. The other was about seeing an internet celebrity and asked: "If a shopping website invited your favorite Internet celebrity to stream an event for an hour, would you want to watch?" $(M=4.10, S D=.81)$.

\section{Results}

To better understand users' shopping websites, we asked, "Which live streaming shopping sites have you used? You may choose more than one". The descriptive results showed that most of participants had used Amazon "Style Code Live" (62.4\%), followed by Live.me (23.6\%), VIP.com (7.5\%), Taobao.com (7\%), JD.com (4\%), Livby (4\%), and other (34.7\%).
For the second research question, we put the main motivations as independent variables into a regression model and put the three intentions as separate dependent variables. We also wanted to see whether demographic information (age, income, gender) had effects on intentions. Control variables included internet usage and shopping frequency. Results are reported in Table 2.

For the intention to watch a live stream when shopping in the future $(F(11,187)=13.08, p<.001)$, substitutability of personal examination and trend setting were significant motivations. Frequency of watching live streams in general and age were also significant. They were positively related to this intention, indicating that if live streams on e-commerce websites could provide more sensory elements of a physical product that could acceptably substitute for directly individual touch and examination, or if consumers were willing to popularize or initiate shopping trends, they would like to watch while shopping. The more often they watched live streams, the more likely they would be to watch when shopping online. Interestingly, age was strongly positively related to this intention, suggesting that if the consumers were older, they were more likely to watch live streams when shopping in the future. $40 \%$ of total variance was explained by this model. 
The intention to watch a live stream if an individual was searching for a product online and just happened to find a live streaming event $(F(11,187)=5.94, p<.001)$ was positively and significantly explained by the same motivations as the first intention: substitutability of personal examination and trend setting, implying that the higher substitutability of personal examination, or the stronger willingness to be trend setters, the higher likelihood people would have to click and watch while searching for the product. $22 \%$ of variance was explained by this model. Compared to first intention, it had no significant frequency or demographic factor.

The third intention asked participants that if an ecommerce website invited an internet celebrity whom people admired to stream a promotion event, whether they would like to watch. The model was significant $(F$ $(11,187)=5.97, p<.001)$. Enjoyment of interaction and trend setting were significant motivations, suggesting that if consumers were trend setters or could have an enjoyable interaction with the celebrity and other viewers, they preferred to watch live streams before purchasing. Frequency of shopping online after watching a live stream that was not part of the shopping website was negatively associated with the celebrity scenario, indicating that the more frequently they shopped online after watching live streams somewhere else, the less likely they would be to watch live streams on e-commerce websites that internet celebrities participated in. $22 \%$ of variance was explained by this model.

\section{Discussion}

The results of the regression models showed that only three motivations were associated with three intentions and need for community was insignificant with all of them. Several design implications could be considered for current and future live streaming commerce system.

No matter whether consumers intended to generally watch live streams or search products, substitutability of personal examination was strongly related, indicating that e-commerce platforms could use live streaming service to increase sensory components and to enhance product demonstration and information provision. Current e-commerce businesses, such as Amazon and BestBuy, provide product details such as descriptions and reviews, but it is still difficult to evaluate the quality of products to some extent. For example, if a non-tech consumer needed to buy tech products but couldn't understand the configuration on the webpage, maybe a tech expert could do live streams to introduce the product and show its performance. This way would assist consumers to better judge the product and increase the likelihood of purchasing.

Live streaming on e-commerce platforms could provide more detailed and authentic information to help customers make better decisions. Most people still prefer to shop for clothing in physical stores instead of online because it is hard to get the style and size fit even though current shopping sites provide details of products and model images. Through live streams, a streamer could introduce him/herself with height, weight, size etc. and then show the clothing on her/him and evaluate the comfort level and materials. The streamer could even teach you how to match different styles with specific clothes.

One main feature of live streaming commerce was real-time interaction. According to the results of the celebrity scenario, we noticed that enjoyment of interaction was significant, but substitutability of personal examination was not, implying that if consumers' admired internet celebrities were invited to promote for e-commerce websites, consumers may come and watch with no matter what the product is. Live streaming commerce might provide potential marketing strategies for homogeneous products by inviting internet celebrities to do marketing campaigns instead of using expensive commercials. Their fans would be directly transferred into potential customers and would make the product stand out from the crowd.

Trend setting was consistently associated with all scenarios, suggesting new features or methods to motivate trend setters should be investigated. Some cool features in live streams such as augmented animation could be implanted into live streaming commerce to increase entertainment. Virtual reality features might also be embedded into live streaming commerce to enhance immersive experience.

From the literature, we saw that need for community was an important motivation for live streaming communities. However, when it was extended to live streaming commerce, it was not significant. We assumed that the streamers and consumers formed an online shopping community there based on aforementioned literature. However, we couldn't answer "why" need for community was not associated. The potential explanation might be due to the shopping attribute that once consumers shopped a certain product, they wouldn't like to come back and shop again in a short time. The stickiness between consumers and streamers on live streaming commerce platforms was very low and the ultimate goal for consumers was still shopping, not seeking social support or making friends. Therefore, even if the community existed, the need for community was not strong enough to be significant in explaining future shopping intentions. We do not know from these cross-sectional results, however, whether the 
current design of live shopping e-commerce is not suitable for community formation or if the domain of shopping itself is less about community. Further qualitative research should be conducted to explain how community dynamics work in this space and the contextual factors that are associated with the importance of need of community in this domain.

There are several limitations in this research. First, live streaming commerce is a very new genre, thus only a small group of people had this shopping experience. To make sure we could obtain enough qualified data in a time period, we used Amazon Mechanical Turk for convenience, so our samples might be a little biased toward people who are tech-savvy, which certainly does not represent the global consumer population. Also, this is a U.S.-based study (most of participants are from United States and used Amazon "Style Code Live"), but live streaming commerce is more popular in Asia. Therefore, the results are limited to the boundaries of our sample. Future research may want to look into Asia markets to compare the results and explore the difference. Finally, we used survey methods and quantitative methods are appropriate in identifying statistical patterns but do not fully explain "why". For example, why is age positive and only associated with general watching scenarios? Other methodologies should be applied such as qualitative research, to better understand the nuances of live streaming commerce.

\section{Conclusion}

Based on previous literature and the uses and gratifications framework, this research identified four motivations (enjoyment of interaction, substitutability of personal examination, need for community, and trend setting) of live streaming commerce and explored the relationships between these motivations and behavioral intentions in specific scenarios. The results showed that only three motivations had positively significant linear relationships with the three intentions. Specifically, substitutability of personal examination and trend setting could predict intentions related to the general watching and product search scenarios; enjoyment of interaction and trend setting could predict the intention that involved in internet celebrities. Need for community was not associated with any scenario.

Most of the demographic factors and watching live streams and shopping frequencies were not associated, but two shopping frequencies are significantly related to two different scenarios. Specifically, frequency of watching live streams in general was positively associated with the intention to watch live streams in general and frequency of shopping online after watching a live stream on a shopping website was negatively associated with the intention to watch live streams if the admired streamers were invited to stream an event. Age was positively associated with the general watching scenario. Further research could explore the demographic and frequency difference among different scenarios.

Surprisingly, the need for community was not associated with any scenario while trend setting was significant for all scenarios. This needs further investigation and could also be something that is reflective of the very early usage patterns of live streaming commerce. These results could provide some hints for current e-commerce businesses that plan to evolve into live streaming commerce.

\section{References}

[1] Bründl, S., and T. Hess, "Why Do Users Broadcast? Examining Individual Motives and Social Capital on Social Live Streaming Platforms", PACIS 2016

Proceedings(January), 2016, pp. Paper 332.

[2] Cai, J., D.Y. Wohn, A. Mittal, and D. Sureshbabu, "Utilitarian and Hedonic Motivations for Live Streaming Shopping", ACM Conference on Interactive Experiences for Television and Online Video (TVX), (2018).

[3] Chai, J.X., and K.K. Fan, "User satisfaction and user loyalty in mobile SNSs: WeChat in China", 2016

International Conference on Applied System Innovation, IEEE ICASI 2016, (2016).

[4] Chen, G.M., "Tweet this: A uses and gratifications perspective on how active Twitter use gratifies a need to connect with others", Computers in Human Behavior 27, 2011, 755-762.

[5] Childers, T.L., C.L. Carr, J. Peck, and S. Carson, "Hedonic and utilitarian motivations for online retail shopping behavior", Journal of Retailing 77(4), 2001, pp. 511-535.

[6] Chiu, C.M., M.H. Hsu, and E.T.G. Wang, "Understanding knowledge sharing in virtual communities: An integration of social capital and social cognitive theories", Decision Support Systems 42(3), 2006, pp. 18721888 .

[7] Crossler, R.E., "Intention to Engage in Social Commerce : Uses and Gratifications Approach", Twentieth Americas Conference on Information Systems, (2014), 1-12.

[8] Davis, F.D., R.P. Bagozzi, and P.R. Warshaw, "Extrinsic and Intrinsic Motivation to Use Computers in the Workplace", Journal of Applied Social Psychology 22(14), 1992, pp. 1111-1132.

[9] Delacharlerie, C., "Why is 'live shopping' a hit in China?", Innovation Is Everywhere, 2017. 
https://www.innovationiseverywhere.com/live-shopping-hitchina/

[10] Friedländer, M.B., "JISTaP Streamer Motives and UserGenerated Content on Social Live-Streaming Services", J Inf Sci Theory Pract JISTaP 55(11), 2017, pp. 65-84.

[11] Gareth, L.W.F., "The Study of Mobile Game Loyalty: The Need Gratification and Flow Experience Approach", 2013.

https://pdfs.semanticscholar.org/791b/a12d710723f1cde6756 fb2a4ef395e78b7c8.pdf

[12] Gros, D., B. Wanner, A. Hackenholt, P. Zawadzki, and K. Knautz, "World of streaming. Motivation and gratification on twitch", Lecture Notes in Computer Science (including subseries Lecture Notes in Artificial Intelligence and Lecture Notes in Bioinformatics), (2017), 44-57.

[13] Haimson, O.L., and J.C. Tang, "What Makes Live Events Engaging on Facebook Live, Periscope, and Snapchat", Proceedings of the 2017 CHI Conference on Human Factors in Computing Systems - CHI '17, (2017), 48-60.

[14] Hamilton, W.A., O. Garretson, and A. Kerne, "Streaming on twitch: fostering participatory communities of play within live mixed media", Proceedings of the SIGCHI Conference on Human Factors in Computing Systems, 2014, pp. 1315-1324.

[15] Haridakis, P., and G. Hanson, "Social interaction and co-viewing with YouTube: Blending mass communication reception and social connection", Journal of Broadcasting and Electronic Media 53(2), 2009, pp. 317-335.

[16] Huang, Z., and M. Benyoucef, "From e-commerce to social commerce: A close look at design features", Electronic Commerce Research and Applications 12(4), 2013, pp. 246259.

[17] Joines, J.L., C.W. Scherer, and D.A. Scheufele, "Exploring motivations for consumer Web use and their implications for e-commerce", Journal of Consumer Marketing 20(2), 2003, pp. 90-108.

[18] Joinson, A.N., “'Looking at', 'looking up' or 'keeping up with' people? Motives and uses of Facebook", CHI 2008 Proceedings: Online Social Networks, (2008), 1027-1036.

[19] Kaplan, A.M., and M. Haenlein, "Users of the world, unite! The challenges and opportunities of Social Media", Business Horizons 53(1), 2010, pp. 59-68.

[20] Katz, E., J.G. Blumler, and M. Gurevitch, "Uses and Gratifications Research", Public Opinion Quarterly 37(4), 1973, pp. 509.

[21] Katz, E., J.G. Blumler, and M. Gurevitch, The uses of mass communication:Current Perspectives on Gratifications Research, 1974.
[22] Kaytoue, M., A. Silva, and L. Cerf, "Watch me playing, i am a professional: a first study on video game live streaming", Proceedings of the 21st international conference companion on World Wide Web, 2012, pp. 1181-1188.

[23] Khoo, C.S.G., "Issues in Information Behaviour on Social Media", Proceedings of the ISIC Workshop on Information Behaviour on Social Media 24(2), 2014, pp. 7596.

[24] Kim, S., and H. Park, "Effects of various characteristics of social commerce (s-commerce) on consumers' trust and trust performance", International Journal of Information Management 33(2), 2013, pp. 318-332.

[25] Lim, W.M., and D.H. Ting, "E-shopping: An analysis of the uses and gratifications theory", Modern Applied Science 6(5), 2012, pp. 48-63.

[26] Liu, X., "Live streaming in China: boom market, business model and risk regulation", Journal of Residuals Science \& Technology 13(8), 2016, pp. 1-7.

[27] Marsden, P., Social Commerce: Monetizing Social Media (white paper), Syzygy Group, 2010.

[28] Marszałek, W., "Introduction to Live-Streaming in China”, Nanjing Marketing Group, 2017. https://www.nanjingmarketinggroup.com/blog/livestreaming-china

[29] Matikainen, J., "Motivations for content generation in social media", Journal of Audience \& Reception Studies 12(1), 2015, pp. 41-58.

[30] Pires, K., and G. Simon, "YouTube Live and Twitch: A Tour of User-Generated Live Streaming Systems", Proceedings of the 6th ACM Multimedia Systems Conference on-MMSys '15, (2015), 225-230.

[31] PR Newswire, "Livby Launches The First Mobile Live Streaming Shopping App", PR Newswire, 2016.

http://eds.b.ebscohost.com.libdb.njit.edu:8888/ehost/detail/de tail? vid $=18 \&$ sid $=$ c83b1947-0faa-40fc-9d58-

0 ac21e28e5ac\%40pdc-v-

sessmgr01\&bdata=JnNpdGU9ZWhvc3QtbG12ZQ\%3D\%3D\# $\mathrm{AN}=201612130900 \mathrm{PR}$. NEWS.USPR.LA67806\&db=bwh

[32] Raacke, J., and J. Bonds-Raacke, "MySpace and Facebook: Applying the Uses and Gratifications Theory to Exploring Friend-Networking Sites", CyberPsychology \& Behavior 11(2), 2008, pp. 169-174.

[33] Rubin, A.M., "Uses and gratificantions perpective on media effects", In Media effects: Advances in theory and research. 2008, 165-182.

[34] Ruggiero, T.E., "Uses and Gratifications Theory in the 21 st Century”, Mass Communication and Society 3(1), 2000, pp. 3-37. 
[35] Scheibe, K., K.J. Fietkiewicz, and W.G. Stock, "Information Behavior on Social Live Streaming Services", Journal of Information Science Theory and Practice 4(2), 2016, pp. 6-20.

[36] Shadkam, M., and J. O'Hara, "Social commerce dimensions: The potential leverage for marketers", Journal of Internet Banking and Commerce 18(1), 2013.

[37] Sjöblom, M., and J. Hamari, "Why do people watch others play video games? An empirical study on the motivations of Twitch users", Computers in Human Behavior 75, 2017, pp. 985-996.

[38] Sjöblom, M., M. Törhönen, J. Hamari, and J. Macey, "Content structure is king: An empirical study on gratifications, game genres and content type on Twitch", Computers in Human Behavior 73, 2017, pp. 161-171.

[39] Smith, M., “Amazon's attempt to reinvent TV shopping has failed", engadget.com, 2017.

https://www.engadget.com/2017/05/31/amazon-style-codelive-tv-shopping-cancelled/

[40] Talkshoplive, "Talkshoplive Launches The First Ever Live-Streaming Social Selling Network", PR Newswire, 2018. https://www.prnewswire.com/news-

releases/talkshoplive-launches-the-first-ever-live-streamingsocial-selling-network-300611655.html

[41] Tang, J.C., G. Venolia, and K.M. Inkpen, "Meerkat and Periscope: I Stream, You Stream, Apps Stream for Live Streams", Proceedings of the 2016 CHI Conference on Human Factors in Computing Systems - CHI '16, ACM Press
(2016), 4770-4780

[42] Veloso, E., V. Almeida, W. Meira, A. Bestavros, and S. Jin, "A hierarchical characterization of a live streaming media workload", IEEE/ACM Transactions on Networking 14(1), 2006, pp. 133-146.

[43] Vieira, A.B., A.P.C. da Silva, F. Henrique, G. Goncalves, and P. de Carvalho Gomes, "SopCast P2P Live Streaming: Live Session Traces and Analysis", Proceedings of the 4th ACM Multimedia Systems Conference on - MMSys '13, (2013), 125-130.

[44] Wohn, D.Y., G. Freeman, and C. McLaughlin, "Explaining Viewers' Emotional, Instrumental, and Financial Support Provision for Live Streamers", Proceedings of the 2018 CHI, ACM Press (2018).

[45] Yang, X., and G. Li, "Exploring social commerce adoption in china: A uses and gratifications perspective", Proceedings - Pacific Asia Conference on Information Systems, PACIS 2014, (2014).

[46] Zakrzewski, C., "ShopShops Aims at Chinese Consumers Via Live Streaming", The Wall Street Journal, 2018. https://www.wsj.com/articles/shopshops-aims-atchinese-consumers-via-live-streaming-1522957944

[47] Zolkepli, I.A., and Y. Kamarulzaman, "Understanding Social Media Adoption: The Role Of Perceived Media Needs And Technology Characteristics", World Journal of Social Sciences 1(1), 2011, pp. 188-199.

[48] "Popshop Live | Crunchbase", https://www.crunchbase.com/organization/popshop-live 